\title{
Tendências do cenário energético brasileiro: a energia de fonte eólica e o "olhar" dos atingidos
}

\author{
Djane Barbosa Leite, Ênio Pereira de Souza \\ Universidade Federal de Campina Grande - UFCG, Brasil.
}

\section{Resumo}

Assunto da ordem do dia na agenda ambiental, a matriz energética das sociedades contemporâneas, vem sendo pensada a partir da procura de novas fontes para inclusão no mix energético, a exemplo da eólica. Neste contexto, preponderam dois fatores estratégicos: a busca da expansão da oferta energética para garantia de suprimento das demandas, e a procura do meio político de diversos países de diminuir as emissões de dióxido de carbono, divulgando ter em vista o combate ao aquecimento global. O presente trabalho é contextualizado, e tem por objetivo discutir, sob um prisma comparativo, a forma como vem ocorrendo a transformação de territórios, no Brasil, para apropriação dos bens ambientais que sustentam a matriz energética, observando, primeiramente, a matriz que se apoia nas hidrelétricas, passando, em seguida, para a de fonte eólica. O estudo, que reúne as perspectivas apresentadas na literatura sobre a apropriação dos bens ambientais e suas consequências, a caracterização da energia eólica e sua atual situação no país, e a maneira como está ocorrendo o envolvimento dos grupos sociais atingidos por empreendimentos energéticos, levou à percepção da importância de se incluir a participação dos referidos grupos nos processos decisórios de projetos de empreendimentos energéticos.

Palavras-chave: Matriz energética. Bens ambientais. Energia eólica. Grupos atingidos. Participação.

\begin{abstract}
A subject of great relevance in the environmental field, the energy matrix of contemporary societies is being designed based on the search for new sources to include in the energy mix, such as the wind. In this context, two strategic factors predominate: the pursuit of expanding energy supply to guarantee supply demand, and the search by the politics of many countries to reduce carbon dioxide emission, broadcasting a fight against global warming. This work is contextualized, and aims to discuss, by means of a comparative look, the way that the transformation of territories in Brazil have been occurring for allocation of environmental assets that give sustenance to the energy matrix, first noting the matrix that is based on hydropower, and then to wind-source energy. The study brings together the perspectives presented in literature about the appropriation of environments and its consequences, the characterization of wind energy and its current situation in the country, and how the involvement of social groups affected by energy projects has led to the perception of the importance of including the participation of these groups in the decision making processes of energy-developing projects.
\end{abstract}

Key words: Energy matrix. Environmental assets. Wind energy. Affected groups. Participation. 


\section{Notas introdutórias: a apropriação dos bens ambientais e algumas consequências}

Ao longo dos percursos históricos, o homem buscou no meio ambiente as condições necessárias para o seu desenvolvimento, engendrando as mais variadas formas de transformação dos espaços que tivessem recursos que satisfizessem as suas necessidades. Tal fenômeno, contudo, muitas vezes se deu - e ainda se dá - de forma desarmoniosa, sem considerar todas as vertentes que se apresentam nos cenários postos.

Assim, o que se vem observando, na contemporaneidade, em espaços como a Zona Costeira, a Amazônia, o Cerrado, entre outros, é a expansão do capital sobre territórios tradicionalmente ocupados por grupos sociais com modos de vida próprios, na maioria das vezes ainda desvinculados da mercantilização integral.

Desta forma, várias consequências socioambientais estão envolvidas na inclusão de "novas territorialidades" como passíveis de apropriação por conta do interesse de alguns setores econômicos, como, por exemplo, os setores de energia, infraestrutura, agronegócio.

Este trabalho tem por objetivo discutir, a partir de um prisma comparativo, a forma como vem se dando a transformação de territórios, no Brasil, para apropriação dos bens ambientais que dão sustento à matriz energética, observando, primeiramente, a matriz que se apoia nas hidrelétricas, passando, em seguida, para a de fonte eólica.

\section{A energia eólica}

Segundo Fadigas (2011), embora não se saiba exatamente desde quando se usa a energia eólica, dados históricos indicam que a utilização da mesma não é recente, e que os "moinhos de vento" surgiram na Pérsia por volta de 200 a. C., sendo que os chineses também os utilizavam para drenarem seus campos de arroz.

(...) As máquinas primitivas de eixo vertical persistiram até o século XII, quando os moinhos de vento de eixo horizontal do tipo holandês começaram a ser usados em larga escala em vários países da Europa, tais como Inglaterra, França e Holanda. (...) Os moinhos na Europa tiveram, sem dúvida, um forte e decisiva influência na economia agrícola por vários séculos substituindo a força humana e animal. (...) Com o surgimento da máquina a vapor no século 19, iniciou-se o declínio da energia eólica na Holanda e em outros países europeus. (FADIGAS, 2011, p, 09 11).

Por meio dos aerogeradores, a transformação da energia dos ventos em eletricidade começou na segunda metade do século XIX. "Antes da I Guerra Mundial, a Alemanha iniciou a fabricação de turbinas eólicas que nada mais eram que cata-ventos, modelos americanos adaptados para geração de eletricidade" (FADIGAS, 2011, p. 13).

Na Rússia e nos Estados Unidos, o empenho em desbravar o território, aliado à grande dimensão espacial, fez com que os aerogeradores constituíssem uma boa alternativa para a alimentação de edificações rurais isoladas. Naquele último país, a resolução da questão do fornecimento de energia elétrica às áreas rurais ensejou para o país o desenvolvimento de turbinas eólicas de maior potência, cujo objetivo era conectá-las às redes elétricas públicas interligadas às centrais elétricas convencionais.

Após a II Guerra Mundial, a disponibilidade e os baixos preços do petróleo e do carvão mineral tornaram a geração de eletricidade com base nesses combustíveis 
economicamente mais atrativa, ensejando que o desenvolvimento de turbinas eólicas ficasse restrito a algumas pesquisas.

Em uma dessas pesquisas, entre 1958 e 1966, a Alemanha "construiu e operou um aerogerador com o maior número de inovações tecnológicas da época. Os avanços tecnológicos desse modelo persistem até hoje na concepção dos modelos atuais, o que mostra o seu sucesso de operação" (FADIGAS, 2011, p. 17).

Na década de 1970, o abalo da economia mundial, em decorrência das sucessivas crises do petróleo, propiciou a retomada de investimentos mais expressivos em energia eólica (bem como em outras fontes energéticas), notadamente nos Estados Unidos e na Alemanha, que passaram a desenvolver mais estudos, testando e aprimorando modelos de turbinas eólicas.

Nos últimos anos, esse comércio, no mundo, desenvolveu-se rapidamente em termos de tecnologia e tamanho, e o nível tecnológico continua sendo aperfeiçoado (materiais mais leves, estruturas mais simples etc.), buscando, inclusive, reduzir custos de tecnologias em sítios onshore. O desenvolvimento de turbinas para aplicação offshore, apesar de estar em acelerada fase de exploração, ainda não atingiu um fase madura.

\footnotetext{
O crescimento da indústria eólica na Europa e nos Estados Unidos possibilitou investimentos privados direcionados a modelos cada vez maiores para o mercado onshore e também para o incipiente e promissor mercado offshore. Países como Dinamarca, Alemanha, Inglaterra, Suécia e Holanda, entre outros, possuem planos para instalação de centrais eólicas offshore. (FADIGAS, 2011, 22 - 24).
}

Costa (2006, p. 65) alerta que, na Alemanha, onde a energia eólica ultrapassou, desde 2004, a hidreletricidade, existem sinais de uma diminuição na tendência de energia eólica onshore, notadamente devido ao limitado número de locais apropriados à instalação de empreendimentos.

No Brasil, a primeira turbina eólica foi instalada em 1992, no Arquipélago de Fernando de Noronha, já que, os primeiros dados anemométricos do Brasil, nos anos 1970, que mostravam velocidades médias anuais da ordem de $4 \mathrm{~m} / \mathrm{s}$ a $10 \mathrm{~m}$ de altura, apontavam o litoral do Nordeste e o arquipélago de Fernando de Noronha como sítios mais promissores para a geração eólio-elétrica (BRASIL, 2008); outra instalação antiga é a Central Eólica Experimental no Morro de Carmelinho, instalada em 1994, em Gouveia/MG, e, de 2003 em diante, várias centrais eólicas foram sendo instaladas no país, desencadeadas pelo impulso dado pelo "Programa de Incentivos às Fontes Alternativas de Energia" (Proinfa), instituído pela lei $\mathrm{n}^{\circ} 10.438 / 2002$, como será mostrado adiante.

\section{O cenário energético no Brasil e a energia eólica}

Nas últimas três décadas, houve uma alteração considerável na participação dos diversos recursos energéticos primários no atendimento da demanda por energia, com a crescente inclusão, em vários países, de fontes renováveis, as quais estabeleceram um lugar firme no mix energético, estando em franca expansão, notadamente após o estabelecimento, pela União Europeia, de metas ambiciosas dessas modalidades (GERMANY, 2009, p. 37); contudo, a utilização massiva dos combustíveis fósseis, que há tempos vem sustentando a matriz energética das sociedades, ainda vem predominando na matriz energética mundial (BRASIL, 2007, p. 69), e, na realidade, como aponta Abramovay (2014, p. 2), citando Ayres e 
Ayres (2011), a matriz energética mundial será dominada pelos fósseis até meados do século XXI.

No cenário mencionado de crescente inclusão de novas fontes energéticas, preponderam dois fatores estratégicos: a busca da expansão da oferta energética para garantia de suprimento, e a procura do meio político de diversos países de diminuir as emissões de dióxido de carbono, divulgando ter em vista o combate ao aquecimento global.

O Brasil é identificado como potência energética mundial, uma vez que é considerado rico em alternativas de produção das mais variadas fontes, tendo, paulatinamente, diversificado a sua matriz energética (destacadamente devido à preocupação com a dependência externa dos combustíveis fósseis), e mantido o alto índice de energia renovável que sempre a caracterizou (BRASIL, 2007, p. 168 -169).

Assim, a matriz energética brasileira, "que hoje já possui forte participação das fontes renováveis de energia (hidráulica, eólica, etanol, biomassa, entre outras), contará com uma predominância ainda maior dessas fontes dentro de um prazo de dez anos" (TOLMASQUIM, 2012, p. 249).

Especificamente quanto à geração de energia elétrica, na matriz brasileira, há predomínio das hidrelétricas, e, de 2010 para 2011, houve um aumento da participação das renováveis, incluindo a eólica, na produção de eletricidade (BRASIL, 2012, p. 31).

No Brasil, a iniciativa pioneira de incentivo, que objetivou, efetivamente, impulsionar o uso das chamadas "novas fontes renováveis de energia" (eólica, biomassa e Pequenas Centrais Hidrelétricas ou " $\mathrm{PCH}$ "), adveio da edição da lei $\mathrm{n}^{\circ} 10.438 / 2002$, que criou o Proinfa, o qual, em síntese, fixou metas e meios para participação de tais fontes no sistema interligado nacional.

Assim, não obstante os problemas iniciais verificados quanto aos projetos de geração de energia de fonte eólica a partir do Proinfa ${ }^{1}$, que ensejaram revisão e ajustes por parte do Ministério de Minas e Energia em 2008, vem ocorrendo um aumento da participação da referida fonte no cenário energético brasileiro, com a instalação de empreendimentos eólicos, aproveitando-se o potencial do país, "que é favorecido em ventos, que se caracterizam por uma presença duas vezes maior que a média mundial e com uma variabilidade menor em uma área extensa, que o torna mais previsível". (FADIGAS, 2011, p. 34).

Tolmasquim (2012, p. 253) ressalta que a energia eólica vem apresentando significativa redução de custo ao longo dos últimos anos, sendo que, se em 2005, a preços atualizados, ela só era viável a $300 \mathrm{R} \$ / \mathrm{MW}$, em 2011, foi comprada nos leilões ao preço médio de 99 R\$/MW e 105 R\$/MW.

O mesmo autor prevê que a capacidade instalada do Sistema Elétrico Interligado Nacional (SIN) deve evoluir de cerca de 110 GW (dezembro de 2010), para 171 GW (dezembro de 2020), e a participação da geração oriunda das novas fontes alternativas (PCH, eólica e biomassa) deve dobrar em dez anos (2010 - 2020) (Figura 01). "A geração eólica será destaque, aumentando de $1 \%$ para $7 \%$ de participação em 2020". (TOLMASQUIM, 2012, p. 253).

${ }^{1}$ Como, por exemplo, a inviabilidade econômica dos empreendimentos a partir dos valores estabelecidos para a compra da energia eólica; o índice de nacionalização dos empreendimentos energéticos, que restringia a entrada de fabricantes internacionais de equipamentos (GREENPEACE, 2008; FADIGAS, 2011). 
Figura 01 - Evolução da capacidade instalada do SIN: situação de 2010 e esperada para 2020

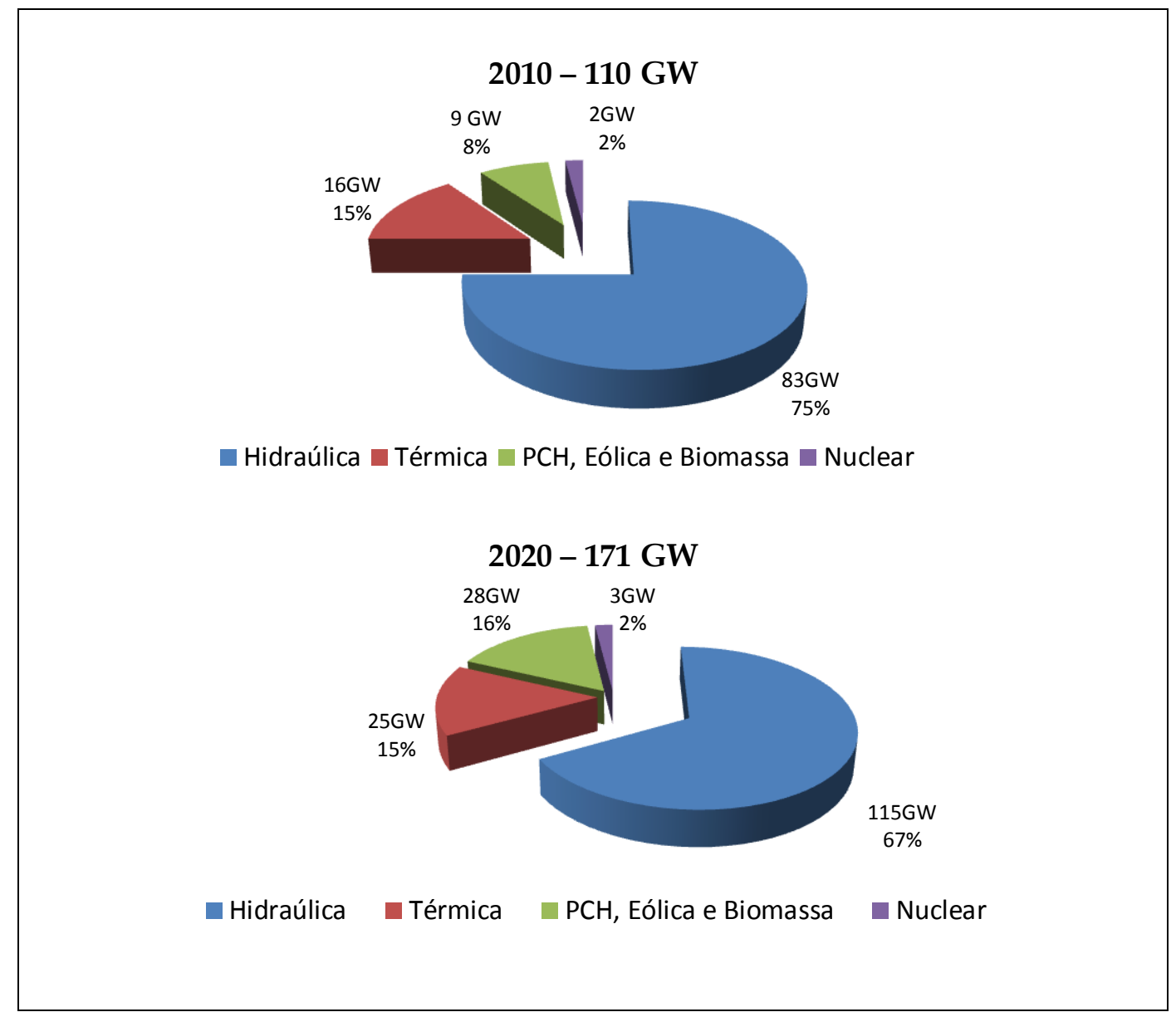

Fonte: Tolmasquim (2012), p. 254

Abramovay (2014) menciona que há uma necessidade verdadeira de transformação da matriz energética de base fóssil, e, inclusive, da que aposta nas hidrelétricas, e que as fontes renováveis, ditas por ele como "modernas" - solar, eólica, biomassa e geotérmica, já contam com aumento da eficiência e redução nos preços.

\section{A energia de fonte eólica e o "olhar" dos atingidos}

No Brasil, o desenvolvimento da política energética esteve vinculado a práticas de inundação, e expulsão de populações para formação de reservatórios e construção de hidrelétricas. Assim, ao longo da história brasileira, grandes projetos hidrelétricos foram sendo empreendidos por decisões tecnocratas, tomadas em gabinete, em parceria com os segmentos interessados nas "benesses" econômicas a serem geradas, sem que houvesse preocupação com os diretamente atingidos - a população do local do empreendimento.

Por isso é que, como apontado nas últimas linhas do tópico anterior, a matriz energética de base hidrelétrica, ainda que oriunda de uma fonte renovável, deve ser 
repensada, uma vez que, constantemente ${ }^{2}$, ignora a população que acaba sendo afetada, pois importa na sua retirada do "lugar" em que habita, espaço socialmente construído, com múltiplas referências e significados, onde ela produz e reproduz o seu modo de vida, o que não deve ser aceitável, por mais que, no processo de deslocamento compulsório, sejam cumpridos os rituais que são esperados, como o pagamento de indenizações, entre outros. O pensamento que vem é de desenraizamento, de perda da identidade individual e coletiva dos atingidos. E as memórias da população, suas construções, sua capacidade de trabalho, via de regra, vinculadas à pluriatividade, suas condições, enfim, sua vida, como ficam? Outras alternativas técnicas e locacionais foram pensadas, cogitadas?

E por falar em energia renovável, estabelecendo uma comparação do cenário acima descrito para as hidrelétricas, com o que vem despontando para a energia de fonte eólica, a qual, como mostrado, tem aumentado, nos últimos anos, a participação no mix energético nacional (e a tendência é que aumente ainda mais), é cabível o dever de alerta, para que não se incorra nos mesmos (des)caminhos quanto aos grupos sociais atingidos.

No país, os melhores potenciais para aplicações em energia eólica são encontrados nas regiões Nordeste e Sul, tanto que a grande maioria dos projetos já implantados no Brasil encontra-se nessas regiões (BRASIL, 2008, p. 23).

Novamente, insiste-se: é necessário não olvidar daqueles grupos sociais diretamente atingidos, via de regra, grupos vulneráveis, que não têm acesso às estruturas decisórias, é dizer, das populações tradicionais que historicamente habitam a vasta zona costeira brasileira ${ }^{3}$ - pescadores artesanais, indígenas, quilombolas - bem como, de uma forma geral, das "comunidades com características naturais" (LASCHEFSKI, 2011, p. 39) ribeirinhos, camponeses, pequenos agricultores - enfim, daquelas populações que têm uma forte identidade e integração com o lugar em que habitam, e, por isso, o percebem como único, para que não se tornem vítimas do avanço dos parques eólicos que vem se instalando, ou virão, certamente, a se instalar, ao longo do país.

Foi a partir dessa constatação - de que a proteção ambiental é desigual, pois existe uma maior exposição das populações vulnerabilizadas aos males ambientais embutidos nos projetos de desenvolvimento - que se teve campo para o surgimento das demandas ligadas à "justiça ambiental" no Brasil.

Assim, no país, deve-se considerar por justiça ambiental condições que importem na garantia de igual proteção aos distintos grupos sociais envolvidos e/ou impactados pelos denominados "projetos de desenvolvimento" (FASE e ETTERN, 2011, p. 19 e 47).

A noção de justiça ambiental implica, pois, o direito a um meio ambiente seguro, sadio e produtivo para todos, onde o "meio ambiente" é considerado em sua totalidade, incluindo suas dimensões ecológicas, físicas construídas, sociais, políticas, estéticas e econômicas. Refere-se, assim, às condições em que tal direito pode ser livremente exercido, preservando, respeitando e realizando plenamente as identidades individuais e de grupo, a dignidade e a autonomia das comunidades. (ACSELRAD et al., 2009, p. 16).

\footnotetext{
${ }^{2}$ Vide os seguintes exemplos ilustrativos: Complexo Energético Capim Branco-MG, Hidrelétrica Candonga-MG, Hidrelétricas do Complexo Madeira-RO e Hidrelétrica de Tucuruí-PA, como mostra Laschefski (2011, p. 23).

${ }^{3}$ Em decorrência da implantação de parques eólicos no litoral cearense, por exemplo, já foi constatada a ocorrência de "privatização" de trechos extensos da costa, entre as comunidades litorâneas tradicionais, incluindo indígenas e quilombolas, e a faixa de praia, restringindo o livre acesso das mesmas aos bens ambientais que historicamente usufruíam, afetando negativamente as suas relações de subsistência com o mar (MEIRELES, 2011).
} 
Para a promoção da justiça ambiental, tem-se um instrumento denominado de "Avaliação de Equidade Ambiental" (AEA), o qual objetiva fortalecer os grupos sociais atingidos por empreendimentos que podem, direta ou indiretamente, afetar seu modo de vida (FASE e ETTERN, 2011, p. 42).

Os preceitos que fundamentam a equidade ambiental são o "tratamento justo", para que nenhum grupo venha a arcar de maneira desproporcional com as consequências ambientais negativas de determinado projeto de desenvolvimento, e o "envolvimento efetivo", que se dá pela possibilidade de participação nas etapas nas quais irão passar tais projetos, desde a sua concepção no planejamento, até o processo de tomada de decisão, com os seus desdobramentos, sendo importante relevar que, para que os atingidos participem, devem ter acesso às informações sobre o projeto.

Ikeme (2003) aponta que a participação das partes interessadas é indispensável para que se proteja o interesse de todos, e que a "marginalização" de um grupo somente tem espaço para ocorrer quando ele tem pouca ou nenhuma influência no processo decisório.

Sensível à questão da insuficiência de participação dos atingidos por empreendimentos nos encaminhamentos que digam respeito aos mesmos, a Rede Brasileira de Justiça Ambiental estabeleceu, como um de seus objetivos, o desenvolvimento de metodologias de avaliação que contemplem os preceitos da equidade ambiental, para complementar os métodos tradicionais atualmente adotados nos estudos ambientais (ACSELRAD et al., 2009, p. 35), e alguns estudos de caso foram realizados, com o intuito de elaborar uma proposta alternativa de avaliação ambiental, e mostrados no "Relatório Síntese Projeto Avaliação de Equidade Ambiental" (FASE e ETTERN, 2011).

\section{Considerações finais}

A questão ambiental está intrinsecamente relacionada ao comportamento humano, notadamente quando diz respeito à apropriação dos bens ambientais para realização das demandas vinculadas à expansão da fronteira capitalista, como é o caso do setor energético e a sua incessante procura por territórios que possam lhes oferecer recursos energéticos de variadas fontes (fóssil, hidráulica, eólica, entre outras).

Contudo, para satisfação das referidas procuras, reiteradamente grupos sociais acabam sendo compulsoriamente expropriados dos seus lugares, com os seus modos de vida e trabalho, como ocorreu - e ainda ocorre - com o desenvolvimento da política energética brasileira, a qual esteve atrelada a práticas de inundação de terras e expulsão de populações para formação de reservatórios e construção de hidrelétricas. Parece haver um desconhecimento da importância da participação efetiva da comunidade no trato das questões que lhes afetam diretamente, como ocorre, por exemplo, quando um grupo social vem a ser atingido pelos projetos de desenvolvimento.

Assim é que a articulação das ponderações expostas neste estudo aponta para a necessidade de os processos decisórios, que envolvem empreendimentos energéticos, viabilizarem a participação efetiva dos grupos sociais diretamente atingidos, notadamente nos ascendentes empreendimentos de fonte eólica, e, para tanto, devem ser disseminadas metodologias que envolvam os preceitos da equidade ambiental, garantindo-se, por conseguinte, a realização de justiça ambiental. 


\section{REFERÊNCIAS}

ABRAMOVAY, Ricardo. Inovações para que se democratize o acesso à energia, sem ampliar as emissões. Ambiente \& Sociedade, São Paulo, v. XVII, n. 3, p. 1-18, 2014.

ACSELRAD, Henri; MELLO, Cecília Campello do Amaral; BEZERRA, Gustavo das Neves. O que é justiça ambiental. Rio de Janeiro: Garamond, 2009.

BRASIL. Ministério das Minas e Energia e Empresa de Pesquisa Energética. Balanço Energético Nacional 2012 (BEN 2012)- Síntese do Relatório Final. Brasília/DF, 2012.

BRASIL. Ministério das Minas e Energia e Empresa de Pesquisa Energética. Plano Nacional de Energia 2030. Outras Fontes. Brasília/DF, 2008.

BRASIL. Ministério das Minas e Energia e Empresa de Pesquisa Energética. Matriz Energética Nacional 2030. Brasília, 2007.

COSTA, Cláudia do Valle. Políticas de promoção de fontes novas e renováveis para geração de energia elétrica: lições da experiência européia para o caso brasileiro. 2006. 249f. Tese (Doutorado em Planejamento Energético) - Instituto Alberto Luiz Coimbra de Pós-Graduação e Pesquisa de Engenharia (COPPE)/Universidade Federal do Rio de Janeiro, Rio de Janeiro, 2006.

FADIGAS, Eliane A. Faria Amaral. Energia eólica. Série Sustentabilidade. Barueri: Manole, 2011.

FASE - Solidariedade e Educação; ETTERN - Laboratório Estado, Trabalho, Territórios e Natureza do Instituto de Pesquisa e Planejamento Regional (IPPUR/UFRJ). Relatório Síntese Projeto Avaliação de Equidade Ambiental. Rio de Janeiro, 2011.

GERMANY. Federal Ministry for the Environment, Nature Conservation and Nuclear Safety (BMU). Electricity from renewable energy sources. What does it cost? Berlin/Germany, 2009.

GREENPEACE. A caminho da sustentabilidade energética: como desenvolver um mercado de renováveis no Brasil. Relatório [r] Revolução Energética. São Paulo, 2008.

IKEME, Jekwu. Equity, environmental justice and sustainability: incomplete approaches in climate change politics. Global Envinronmental Change, 13, p. 195-206, 2003.

LASCHEFSKI, Klemens. Licenciamento e equidade ambiental. As racionalidades distintas de apropriação do ambiente por grupos subalternos. In: ZHOURI, Andréa (org.). As tensões do lugar. Hidrelétricas, sujeitos e licenciamento ambiental. Belo Horizonte: Editora UFMG, 2011.

MEIRELES, Antonio Jeovah de Andrade. Danos socioambientais originados pelas usinas eólicas nos campos de dunas do Nordeste brasileiro e critérios para definição de alternativas locacionais. Confins [Online], 11, 2011. Disponível em http://confins.revues.org/6970. Acesso em 25 mar 2013.

TOLMASQUIM, Maurício Tiomno. Perspectivas e planejamento do setor energético no Brasil. Estudos Avançados, São Paulo, 26 (74), p. 249-260, 2012. 